Research Article

\title{
Evaluation of Conjunctival Autografting Augmented with Mitomycin C Application versus Ologen Implantation in the Surgical Treatment of Recurrent Pterygium
}

\author{
Faried M. Wagdy $(\mathbb{D}$, Hassan G. Farahat, Amin F. Ellakwa $(\mathbb{D}$, and Sameh S. Mandour \\ Department of Ophthalmology, Faculty of Medicine, Menofia University, Shebin El Kom, Menofia, Egypt \\ Correspondence should be addressed to Sameh S. Mandour; dr_ssmandour@hotmail.com
}

Received 14 August 2020; Revised 8 December 2020; Accepted 3 January 2021; Published 12 January 2021

Academic Editor: Paolo Fogagnolo

Copyright (C) 2021 Faried M. Wagdy et al. This is an open access article distributed under the Creative Commons Attribution License, which permits unrestricted use, distribution, and reproduction in any medium, provided the original work is properly cited.

\begin{abstract}
Objectives. To evaluate the safety and efficacy of augmenting conjunctival autografting with intraoperative mitomycin C (MMC) application versus Ologen implantation in the management of recurrent pterygium. Materials and Methods. This prospective randomised study included 63 eyes of 63 patients, with recurrent nasal pterygium, who presented to the outpatient clinic of Menoufia University Hospital in Shebin El Kom and Manshiet Soltan from January 2016 to December 2019. Patients were randomly enrolled into two groups. Group A included 32 eyes of 32 patients who underwent conjunctival autografting augmented with the topical application of MMC $(0.2 \mathrm{mg} / \mathrm{mL})$, and group B included 31 eyes of 31 patients who underwent conjunctival autografting augmented with Ologen implantation. All the patients underwent follow-up examinations for a period of 24 months. During each visit, a complete ophthalmic examination was performed. Pterygium regrowth of $1 \mathrm{~mm}$ or more, over the cornea, was considered a recurrence. Results. In the MMC group, no recurrence was reported during the 24-month follow-up period. In the Ologen implantation group, recurrence was reported in $2(8 \%)$ eyes. The time interval from surgery to recurrence was 5 months in one case and 8 months in the other. No other serious postoperative complications were reported, and there was no statistically significant difference between the groups in this regard. Conclusion. Ologen implantation with conjunctival autografting shows promising results in the surgical management of recurrent pterygium with mild non-vision-threatening postoperative complications comparable to that of MMC application with conjunctival autografting. Registration number: ClinicalTrials.gov NCT04419038.
\end{abstract}

\section{Introduction}

The tendency of pterygia to recur after surgical removal is frustrating for both patients and surgeons [1]. Most ophthalmologists define pterygium recurrence as corneal recurrence, which includes a regrowth of the fibrovascular pterygium-like tissue crossing the limbus onto the cornea, fibrovascular recurrence attaining the same degree of corneal encroachment as the original lesion, or a regrowth exceeding $1 \mathrm{~mm}$ onto the cornea [2].

The risk factors for recurrence include male sex and a history of high sun exposure [3]. Nontranslucent pterygia have been associated with an increased risk of recurrence, as they have several biomarkers related to proliferation, inflammation, fibrosis, and angiogenesis. While the further evaluation of these important biomarkers is needed, they point out the need to develop treatments that target specific receptors in order to achieve the goal of eliminating recurrence [4].

Several surgical techniques and modifications have been used to treat recurrent pterygia. However, none of them have been proven to be completely effective in eliminating further recurrence. A combination of more than one method may usually yield promising results in this regard. Antimetabolites, such as mitomycin C (MMC), and antifibrotic agents, such as Ologen, have been used as adjuvants by many investigators to reduce the possibility of recurrence $[5,6]$.

This study aimed to evaluate the safety and efficacy of augmenting conjunctival autografting with intraoperative MMC application versus Ologen implantation in the management of recurrent pterygium. 


\section{Materials and Methods}

This was a prospective randomised study that included 63 eyes of 63 patients with recurrent nasal pterygium who presented to the outpatient clinic of Menoufia University Hospital in Shebin El Kom and Manshiet Soltan during the period from January 2016 to December 2019

Patients were randomly enrolled into two groups. Group A included 32 eyes of 32 patients who underwent conjunctival autografting augmented with the topical application of MMC $(0.2 \mathrm{mg} / \mathrm{mL})$. Group B included 31 eyes of 31 patients who underwent conjunctival autografting augmented with Ologen implantation.

All patients had a recurrent nasal pterygium after one surgical session for the removal of the primary pterygium. Patients with a primary nasal pterygium, or a recurrent pterygium, who underwent more than one session for the surgical removal were excluded. Patients with cicatrising conjunctival disease or previous conjunctival surgery were also excluded from the study.

A comprehensive ophthalmic examination, including best-corrected visual acuity testing, slit-lamp examination, Goldmann applanation tonometry (whenever possible), fundus examination, and ocular motility examination, was performed for all patients. According to their corneal extent, the pterygia recurrences were classified into 3 grades:

Grade 1: fibrovascular proliferations extend up to onequarter of the corneal diameter.

Grade 2: fibrovascular proliferations extend up to the centre of the cornea.

Grade 3: fibrovascular proliferations extend beyond the visual axis.

Informed consent was obtained from all patients, and the study was approved by the institutional review board. All measures were in accordance with the tenets of the Declaration of Helsinki.

As for group A, $0.2 \mathrm{mg} / \mathrm{mL}$ MMC was prepared by reconstituting a $2 \mathrm{mg}$ vial of mitomycin with $10 \mathrm{~mL}$ of sterile water for injection. When using a $10 \mathrm{mg}$ vial of mitomycin, the same concentration was achieved by first reconstituting it with $10 \mathrm{~mL}$ of sterile water and then diluting $1 \mathrm{~mL}$ of the prepared solution with $4 \mathrm{~mL}$ of saline to achieve a concentration of $0.2 \mathrm{mg} / \mathrm{mL}$ ( $0.02 \%$ solution). This solution was stable for two weeks under refrigeration and for $24 \mathrm{~h}$ at room temperature $\left(59-86^{\circ} \mathrm{F}\right)$.

As for group $\mathrm{B}$, half disc of porous collagen matrix (Ologen $^{\mathrm{TM}}$; Aeon Astron Europe B.V., The Netherlands) was used for each patient. The Ologen disc was $6 \mathrm{~mm}$ in diameter and $2 \mathrm{~mm}$ thick.

\section{Operative Procedure}

All patients underwent surgery under peribulbar anaesthesia. Two radial incisions were made in the conjunctiva and Tenon's capsule at the upper and lower limits of the pterygium belly from the limbus to approximately 4-5 mm towards the inner canthus. The belly was then carefully dissected from the underlying sclera (Figure 1(a)).

The head of the pterygium was dissected from its corneal attachment by reverse stripping using slow and deliberate traction, holding its free end parallel to the cornea (Figure 1(b)).

The fibrovascular tissue underneath the cut end of the conjunctiva was dissected as far as possible on the canthus side and excised, leaving the sclera and medial rectus muscle free from episcleral tissue. Cautery was applied to the bare sclera to control bleeding (Figure 1(c)).

In group $\mathrm{A}, \mathrm{MMC}(0.02 \%)$ was applied using a soaked sponge of $3 \times 4 \mathrm{~mm}$ to the bare sclera area for $2 \mathrm{~min}$, followed by copious irrigation with normal saline. Donor tissue was harvested from the superotemporal conjunctiva of the same eye. The eyeball was rotated down using a superior limbal suture. An area of the conjunctiva larger than the bare sclera area by $1 \mathrm{~mm}$ was measured with callipers and marked with gentian violet (Figure 1(d)). The conjunctiva was elevated with the subconjunctival injection of lidocaine $2 \%$ and epinephrine $1: 100,000$.

Conjunctival scissors were used to make two parallel radial incisions along the marked lines and to undermine the conjunctiva along the lateral borders (Figure 1(e)). When the posterior and lateral ends of the graft were free, blunt dissection was continued anteriorly until the limbus, and a crescent knife or No. 15 blade was used to carry out a further blunt dissection towards the cornea. This dissection continued into the peripheral cornea approximately $1 \mathrm{~mm}$ beyond the vascular arcade. The conjunctival piece was excised using sharp Vannas scissors. The graft was transferred to the bare sclera, epithelial side up, without losing the limbal orientation (the limbal border was identified by its brownish colour that was tough and firm, somewhat characterised by a wavy margin). The epithelial surface was recognised from the stromal side by its smooth and shiny surface, and it was slippery in nature without adherence to the wicks.

The four corners of the graft were then secured using 100 polyamide interrupted sutures (Figure 1(f)).

In group $\mathrm{B}$, Ologen was applied under the graft tissue once it was secured in place (half the vial was used for every patient) (Figures 2(a) and 2(b)). Multiple 10-0 polyamide interrupted sutures were used to fix the graft. The donor site was left open for spontaneous healing.

All patients were re-examined at one week, one month, three months, and once every three months thereafter, for a total period of 24 months. During each visit, a complete ophthalmic examination was performed. A pterygium regrowth over the cornea of $1 \mathrm{~mm}$ or more was considered a recurrence.

Recorded data were analysed using the Statistical Package for Social Sciences, version 16.0 (SPSS Inc., Chicago, Illinois, USA). Quantitative data were expressed as mean\pm standard deviation (SD), and significance was determined using an independent sample t-test. Qualitative data were expressed as frequency and percentage, and significance was tested using a chi square test, with the level of significance set at $95 \%$. 


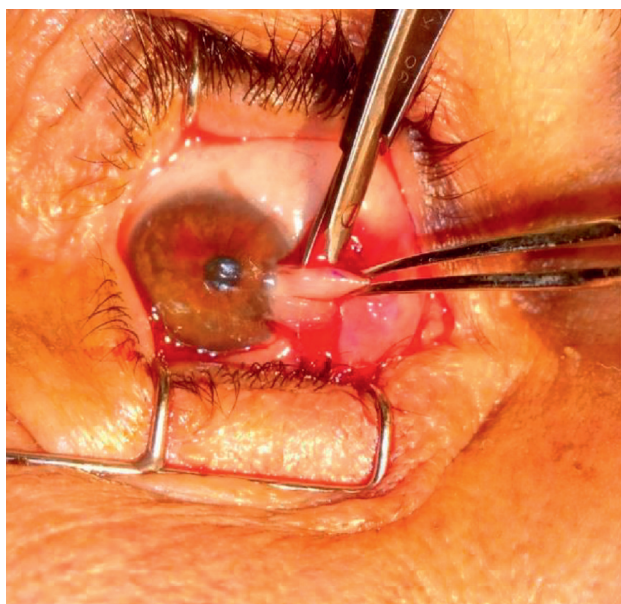

(a)

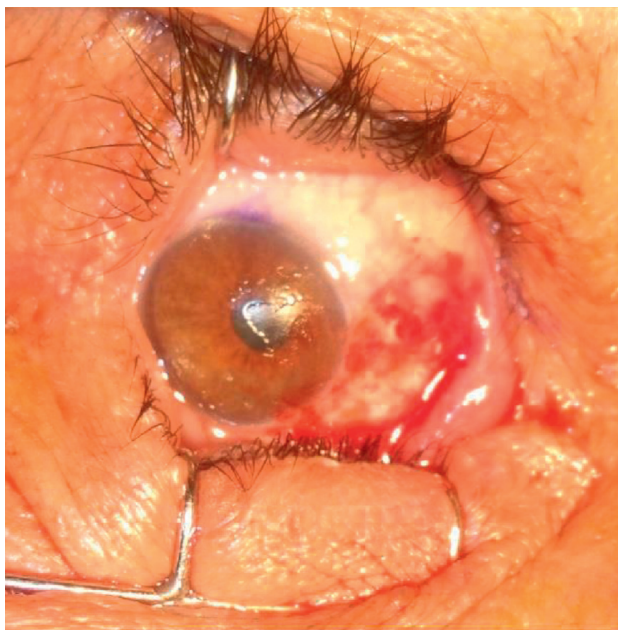

(c)

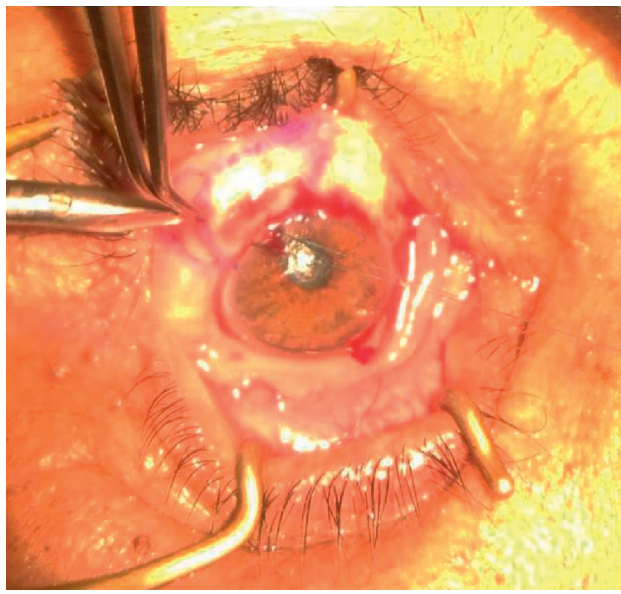

(e)

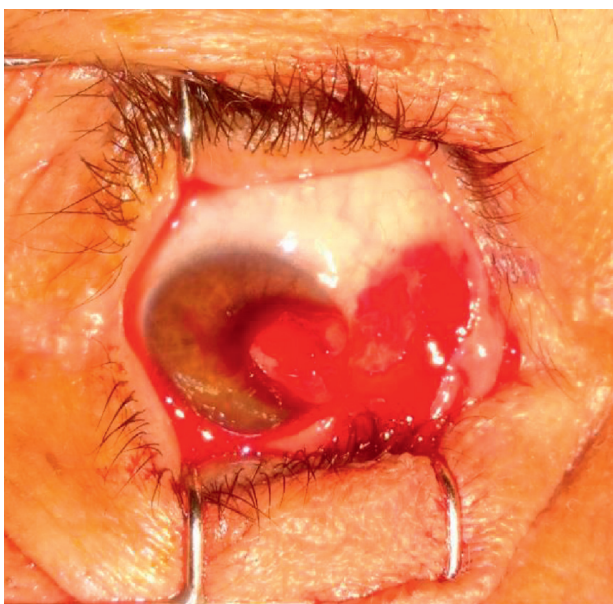

(b)

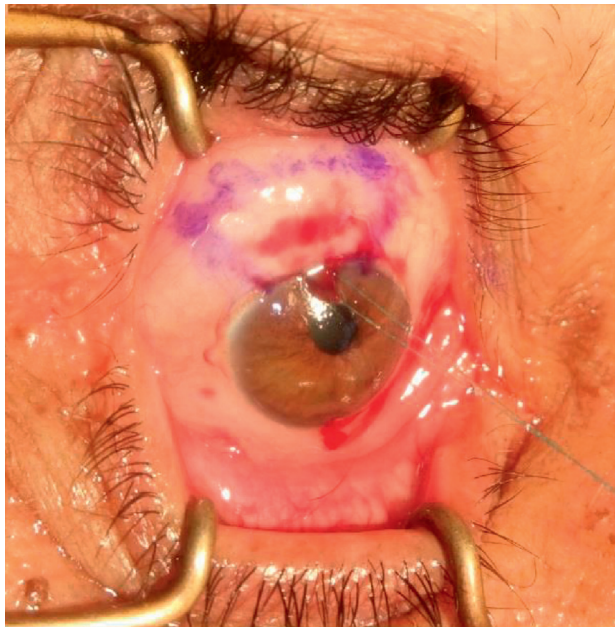

(d)

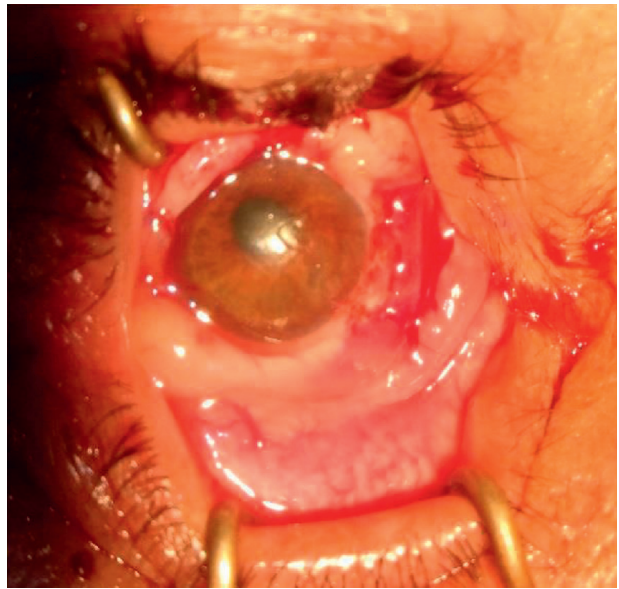

(f)

FIGURE 1: Basic operative technique: (a) dissection of the pterygium from the scleral bed; (b) complete separation of body of pterygium from the scleral bed; (c) bare sclera and cornea after pterygium excision; (d) marking of the conjunctival autograft; (e) dissection of the conjunctival autograft from its bed; (f) suture of the graft to the bare sclera. 


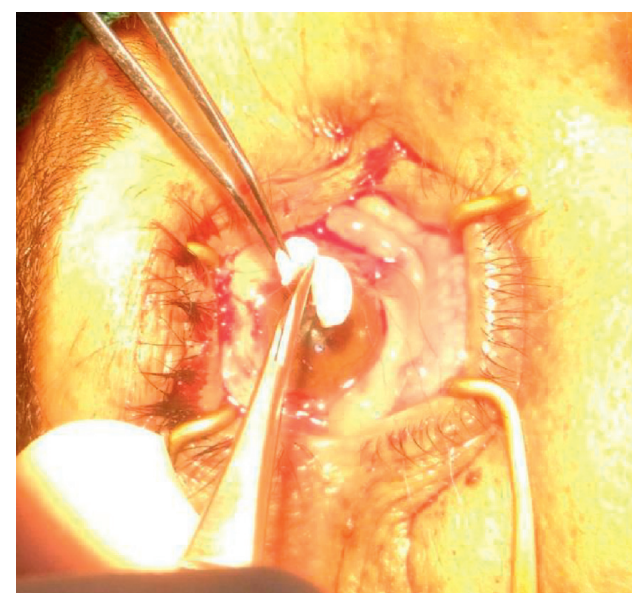

(a)

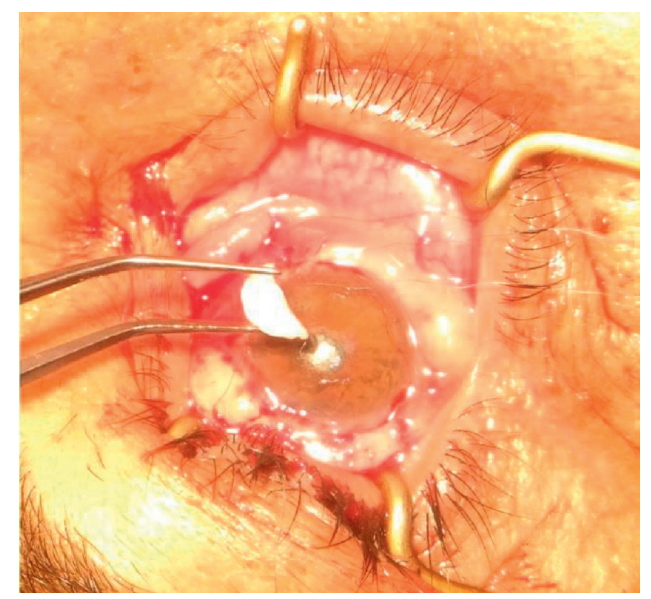

(b)

FIgURE 2: Ologen implantation: (a) cutting Ologen disc into two halves; (b) implanting Ologen under the graft before securing it in place.

\section{Results}

Sixty-three eyes of 63 patients were enrolled in the study, including 32 eyes in group A and 31 eyes in group B. There were $21(58.3 \%)$ men and $11(40.7 \%)$ women in group A and $15(48.4 \%)$ men and $16(51.6 \%)$ women in group B, as shown in Table 1. The mean age of patients in group $A$ was $41.8 \pm 15.98$ years, while the mean age in group B was $46.2 \pm 12.77$ years, with no statistically significant difference between both groups regarding gender and age distribution.

The distribution of the three preoperative clinical grades of pterygia in both groups is shown in Table 2, and the distribution of the indication for surgery in each group is shown in Table 3. The difference between both groups regarding both parameters was statistically insignificant.

Table 4 shows the mean preoperative best-corrected visual acuity (BCVA) as well as the mean postoperative BCVA at the end of the follow-up period in both groups. Mean postoperative BCVA improved; however, there was no statistically significant difference regarding this improvement between both groups.

Regarding postoperative complications, the most important one was the recurrence rate. In group A, no reported recurrence was found during the 24-month follow-up period. In group B, a recurrence was reported in 2 eyes (8\%). The time interval from surgery to recurrence was 5 months in one case and 8 months in the other. There was no statistically significant difference between both groups regarding postoperative recurrence $(P=0.197)$.

Other postoperative complications are summarised in Table 5. No serious postoperative complications were reported. There was no statistically significant difference between the groups in this regard as well.

The two recurrent cases in group B refused further surgery. Their recurrent pterygium was still off centre, and they are still being followed up. The haematomas under the graft were drained through a $1 \mathrm{~mm}$ incision in the graft on the first postoperative day. The granulomas were excised if they were resistant to postoperative medical treatment.

\section{Discussion}

Pterygium is a common eye disease worldwide, especially in tropical and subtropical areas [7]. It is only treated by surgical removal when it affects vision or cosmesis. However, recurrence is the most common postoperative complication. This poses a challenging situation that may affect the integrity and health of the ocular surface in the long run. Recurrent pterygia differ histopathologically from primary pterygia, have higher rates of recurrence with subsequent surgical interventions, and must be considered a different entity from primary pterygia. Recurrent pterygia are also considered to be clinically more aggressive and therefore are more likely to cause visual deficits and other complications [8].

To effectively treat recurrent pterygium, a good understanding of its pathogenesis is crucial. Pterygium is not just a degenerative lesion but could also occur as a result of uncontrolled cell proliferation. Matrix metalloproteinases (MMPs) and tissue inhibitors of MMPs (TIMPs) at the advancing pterygium edge may be responsible for the inflammation, tissue remodelling, and angiogenesis that characterize pterygia, as well as the destruction of Bowman's layer and invasion of the pterygium into the cornea. High levels of vascular endothelial growth factor (VEGF) as well as inflammatory cytokines and mediators were detected in pterygial tissues, relative to normal conjunctiva. It has also been speculated that pterygium may represent an area of localized limbal stem cell deficiency $[2,4]$.

Pterygium excision and conjunctival limbal autograft is considered the gold standard and is currently one of the most commonly used methods for pterygium surgery because of the reported low recurrence rates. However, this method generally results in higher recurrence rates when used for treatment of recurrent pterygium, ranging from $11.3 \%$ to $50 \%$ [9-14]. Recurrence can occur as a result of inadequate peripheral dissection, insufficient graft size, thick graft with Tenon tissue, and graft retraction due to inadequate fixation [8]. For this reason, and to avoid further 
TABLE 1: Distribution of patients in both groups according to their gender.

\begin{tabular}{|c|c|c|c|c|c|c|}
\hline \multirow{3}{*}{ Variable } & \multicolumn{4}{|c|}{ Methods } & \multirow{3}{*}{$x^{2}$} & \multirow{3}{*}{$P$} \\
\hline & \multicolumn{2}{|c|}{ Mitomycin C } & \multicolumn{2}{|c|}{ Ologen } & & \\
\hline & No. & $\%$ & No. & $\%$ & & \\
\hline \multicolumn{7}{|l|}{ Sex } \\
\hline Male & 21 & 58.3 & 15 & 48.4 & 1.9 & 0.17 \\
\hline Female & 11 & 40.7 & 16 & 51.6 & & \\
\hline Total & 32 & 100.0 & 31 & 100.0 & & \\
\hline
\end{tabular}

TABle 2: Distribution of the clinical grades of pterygia in both groups.

\begin{tabular}{|c|c|c|c|c|c|c|}
\hline \multirow{3}{*}{ Variable } & \multicolumn{4}{|c|}{ Methods } & \multirow{3}{*}{$x^{2}$} & \multirow{3}{*}{$P$} \\
\hline & \multicolumn{2}{|c|}{ Mitomycin C } & \multicolumn{2}{|c|}{ Ologen } & & \\
\hline & No. & $\%$ & No. & $\%$ & & \\
\hline \multicolumn{7}{|l|}{ Grade } \\
\hline Grade I & 8 & 25.0 & 9 & 29.0 & \multirow{4}{*}{0.397} & \multirow{4}{*}{0.82} \\
\hline Grade II & 20 & 62.5 & 17 & 54.8 & & \\
\hline Grade III & 4 & 12.5 & 5 & 16.2 & & \\
\hline Total & 32 & 100.0 & 25 & 100.0 & & \\
\hline
\end{tabular}

TABle 3: Distribution of patients in both groups regarding the indications of surgery.

\begin{tabular}{lcccccc}
\hline \multirow{2}{*}{ Variable } & \multicolumn{7}{c}{ Mitomycin C } & \multicolumn{2}{c}{ Ologen } & $x^{2}$ & $P$ \\
& No. & $\%$ & No. & $\%$ & & \\
\hline Indications for surgery & & & & & & \\
$\quad$ Invading or threatening visual axis & 4 & 12.5 & 5 & 16.1 & & \\
$\quad$ Visual impairment due to astigmatism & 11 & 34.4 & 7 & 22.6 & 1.17 & \\
$\quad$ Irritative symptoms and inflammation & 10 & 31.2 & 12 & 38.7 & & \\
Cosmesis & 7 & 21.9 & 7 & 22.6 & \\
Total & $\mathbf{3 2}$ & $\mathbf{1 0 0 . 0}$ & $\mathbf{3 1}$ & $\mathbf{1 0 0 . 0}$ & \\
\hline
\end{tabular}

TABle 4: Comparison between the two groups regarding pre- and postoperative BCVA.

\begin{tabular}{lccc}
\hline \multirow{2}{*}{ Variable } & \multicolumn{2}{c}{ Methods } & $P$ \\
& Mitomycin C & Ologen & \\
\hline Preoperative BCVA & $0.68 \pm 0.22$ & $0.73 \pm 0.21$ & 0.41 \\
Postoperative BCVA & $0.89 \pm 0.12$ & $0.87 \pm 0.19$ & 0.57 \\
\hline
\end{tabular}

recurrence, it is necessary to augment the effect of conjunctival autograft. Adding an adjuvant that acts by decreasing fibrosis would offer the required benefit. Hence, in the current study, the authors combined conjunctival autograft with the intraoperative use of MMC in one group and Ologen implantation in the other.

MMC, an alkylating agent that reduces recurrence by inhibiting fibrovascular growth, has been shown to be a useful adjunct to pterygium surgery [5, 10, 15-17]. An intraoperative topical application of a low-concentration MMC $(0.02 \%$ for $2 \mathrm{~min})$ was shown to be effective in reducing recurrence with minimal risk of serious complications such as scleral melting [18]. Segev et al. reported an even lower recurrence rate of $2 \%$ in a subgroup of patients with recurrent pterygium using MMC $0.02 \%$ for $2 \mathrm{~min}$ and conjunctival graft without serious complications [19].
Considering the safety and efficacy of the combined method using conjunctival autograft and MMC, we used this method in cases of recurrent pterygium.

In the current study, no sight-threatening complications were reported in the MMC group. Moreover, no recurrence was reported during the 24-month follow-up period in this group. However, several studies indicate that severe complications can occur months after the initial treatment; the complications include cataract formation, anterior uveitis, scleral plaque and necrosis, corneal oedema and ulceration, protracted pain, anterior chamber inflammation and nonhealing conjunctival, and corneal and scleral defects [8].

Ologen, a bioengineered, biodegradable, porous collagen-glycosaminoglycan matrix implant, has been developed as an adjuvant to decrease scarring in glaucoma surgery. Ologen reduces conjunctival contraction and promotes the formation of an almost normal subconjunctival stroma [20]. In addition, the matrix improves regenerating tissue remodelling and prevents scar formation or further infection [21].

Ologen was used successfully to minimise scarring in subscleral trabeculectomy [22] and dacryocystorhinostomy [23] and to prevent recurrence after primary pterygium 
TABLE 5: Comparison between the two groups in relation to postoperative complications.

\begin{tabular}{|c|c|c|c|c|c|c|}
\hline \multirow{3}{*}{ Variable } & \multicolumn{4}{|c|}{ Methods } & \multirow{3}{*}{$x^{2}$} & \multirow{3}{*}{$P$} \\
\hline & \multicolumn{2}{|c|}{ Mitomycin C } & \multicolumn{2}{|c|}{ Ologen } & & \\
\hline & No. & $\%$ & No. & $\%$ & & \\
\hline \multicolumn{7}{|l|}{ Postoperative complications } \\
\hline None & 25 & 78.1 & 19 & 61.3 & \multirow{9}{*}{8.338} & \multirow{9}{*}{0.304} \\
\hline Haematoma under graft & 2 & 6.2 & 2 & 6.5 & & \\
\hline Granuloma formation & 0 & 0.0 & 1 & 3.2 & & \\
\hline Infection & 2 & 6.2 & 1 & 3.2 & & \\
\hline Recurrence & $\mathbf{0}$ & 0.0 & 2 & 6.5 & & \\
\hline Suture-related inflammation & 2 & 6.2 & 3 & 9.7 & & \\
\hline Inclusion cyst & 1 & 3.1 & $\mathbf{0}$ & 0.0 & & \\
\hline Graft invasion or retraction & $\mathbf{0}$ & 0.0 & 3 & 9.7 & & \\
\hline Total & 32 & 100.0 & 31 & 100.0 & & \\
\hline
\end{tabular}

removal $[24,25]$. Therefore, the authors in the current study used Ologen as an augmenting agent with conjunctival autografting for recurrent pterygium in the second group of patients. The authors in the current work reported 2 cases of recurrence in this group during the 24-month follow-up period. However, there was no statistically significant difference in recurrence rate between this group and the MMC group.

Other postoperative complications in the current study included haematoma under the graft, granuloma formation, infection, suture-related inflammation, and inclusion cyst and graft invasion or retraction, which were vision-nonthreatening. There was no statistically significant difference between both groups in this regard. This may suggest that it is advantageous to use Ologen as a substitute for MMC, as the topical application of the latter has raised a major concern regarding sight-threatening complications that may even appear later in time $[26,27]$.

However, there were some pitfalls in this study, specifically limiting the candidate patients to those who had only one recurrence episode. The authors plan to apply the same study design and techniques in the treatment of patients with more than one recurrence. The limited number of those patients may mean that more time will be required to recruit enough patients to obtain statistically significant results.

\section{Conclusion}

Ologen implantation with conjunctival autografting shows promising results in the surgical management of recurrent pterygium, comparable to those of MMC application combined to conjunctival autografting, with mild non-vision-threatening postoperative complications.

\section{Data Availability}

Data used to support the findings of this study are available on request from the corresponding author.

\section{Conflicts of Interest}

The authors declare that they have no conflicts of interest.

\section{References}

[1] B. J. Janson and S. Sikder, "Surgical management of pterygium," The Ocular Surface, vol. 12, no. 2, p. 112, 2014.

[2] L. P. Ang, J. L. Chua, and D. T. Tan, "Current concepts and techniques in pterygium treatment," Current Opinion in Ophthalmology, vol. 18, no. 4, pp. 308-313, 2007.

[3] A. Torres-Gimeno, L. Martínez-Costa, and G. Ayala, "Preoperative factors influencing success in pterygium surgery," BMC Ophthalmology, vol. 12, p. 38, 2012.

[4] J. Sheppard, A. Mansur, T. Comstock, and J. Hovanesian, "An update on the surgical management of pterygium and the role of loteprednol etabonate ointment," Clinical Ophthalmology, vol. 8, p. 1105, 2014.

[5] R. Shehadeh-Mashor, S. Srinivasan, C. Boimer, K. Lee, O. Tomkins, and A. R. Slomovic, "Management of recurrent pterygium with intraoperative mitomycin $\mathrm{C}$ and conjunctival autograft with fibrin glue," American Journal of Ophthalmology, vol. 152, no. 5, pp. 730-732, 2011.

[6] L. W. Hirst, "Recurrent pterygium surgery using pterygium extended removal followed by extended conjunctival transplant: recurrence rate and cosmesis," Ophthalmology, vol. 116, no. 7, pp. 1278-1286, 2009.

[7] D. H. K. Ma, L. See, S. Liau et al., "Amniotic membrane graft for primary pterygium: comparison with conjunctival autograft and topical mitomycin C treatment," British Journal of Ophthalmology, vol. 84, no. 9, pp. 973-978, 2000.

[8] J. A. Hovanesian, C. E. Starr, D. T. Vroman et al., "Surgical techniques and adjuvants for the management of primary and recurrent pterygia," Journal of Cataract \& Refractive Surgery, vol. 43, no. 3, pp. 405-419, 2017.

[9] M. Al Fayez, "Limbal versus conjunctival autograft transplantation for advanced and recurrent pterygium," Ophthalmology, vol. 109, no. 9, pp. 1752-1755, 2002.

[10] F. Mutlu, G. Sobaci, T. Tatar, and E. Yildirim, "A comparative study of recurrent pterygium surgery Limbal conjunctival autograft transplantation versus mitomycin $\mathrm{C}$ with conjunctival flap," Ophthalmology, vol. 106, no. 4, pp. 817-821, 1999.

[11] P. Luanratanakorn, T. Ratanapakorn, O. Suwan-Apichon, and R. S. Chuck, "Randomised controlled study of conjunctival autograft versus amniotic membrane graft in pterygium excision," British Journal of Ophthalmology, vol. 90, no. 12, pp. 1476-1480, 2006.

[12] R. S. Figueiredo, E. J. Cohen, J. A. Gomes et al., "Conjunctival autograft for pterygium surgery: how well does it prevent 
recurrence?" Ophthalmic Surgery and Lasers, vol. 28, pp. 99-104, 1997.

[13] A. Sharma, A. Gupta, J. Ram, and A. Gupta, "Low-dose intraoperative mitomycin-C versus conjunctival autograft in primary pterygium surgery: long-term follow-up," Ophthalmic Surgery and Lasers, vol. 31, no. 4, pp. 301-307, 2000.

[14] M. Güler, G. Sobaci, S. Ilker, F. Oztürk, F. M. Mutlu, and E. Yildirim, "Limbal-conjunctival autograft transplantation in cases with recurrent pterygium," Acta Ophthalmologica, vol. 72, no. 6, pp. 721-726, 1994.

[15] P. P. Chen, R. G. Ariyasu, V. Kaza, L. D. LaBree, and P. J. McDonnell, "A randomized trial comparing mitomycin C and conjunctival autograft after excision of primary pterygium," American Journal of Ophthalmology, vol. 120, no. 2, pp. 151-160, 1995.

[16] D. S. C. Lam, A. K. K. Wong, D. S. P. Fan, S. Chew, P.S. K. Kwok, and M. O. M. Tso, "Intraoperative mitomycin C to prevent recurrence of pterygium after excision," Ophthalmology, vol. 105, no. 5, pp. 901-905, 1998.

[17] L. W. Hirst, "Mitomycin C in the treatment of pterygium," Clinical and Experimental Ophthalmology, vol. 34, no. 3, pp. 197-198, 2006.

[18] J. Frucht-Pery, M. Ilsar, and I. Hemo, "Single dosage of mitomycin $\mathrm{C}$ for prevention of recurrent pterygium: preliminary report," Cornea, vol. 13, no. 5, pp. 411-413, 1994.

[19] F. Segev, S. Jaeger-Roshu, N. Gefen-Carmi, and E. I. Assia, "Combined mitomycin C application and free flap conjunctival autograft in pterygium surgery," Cornea, vol. 22, no. 7, pp. 598-603, 2003.

[20] W. C. Hsu, M. H. Spilker, I. V. Yannas, and P. A Rubin, "Inhibition of conjunctival scarring and contraction by a porous collagen-glycosaminoglycan implant," Investigative Ophthalmology \& Visual Science, vol. 41, no. 9, pp. 2404-2411, 2000.

[21] A. Rosenteter, A. M. Schild, J. F. Jordan, G. K. Krieglstein, and T. S. Dietlein, "A prospective randomised trial of trabeculectomy using mitomycin C vs. an Ologen implant in openangle glaucoma," Eye, vol. 24, pp. 1449-1457, 2010.

[22] H. M. Marey, S. S. Mandour, and A. F. Ellakwa, "Subscleral trabeculectomy with mitomycin-C versus ologen for treatment of glaucoma," Journal of Ocular Pharmacology and Therapeutics, vol. 29, no. 3, pp. 330-334, 2013.

[23] H. M. Marey, H. M. Elmazar, S. S. Mandour, and O. A. El Morsy, "Application of biodegradable collagen matrix $\left(\right.$ Ologen ${ }^{\mathrm{TM}}$ ) implants in dacryocystorhinostomy surgeries, a randomised clinical study," BMC Ophthalmology, vol. 18, no. 1 , p. 254,2018

[24] N. Kalra, S. Patyal, P. Dandekar, P. Kumar, G. Kapoor, and S. Puri, "Comparative analysis of outcomes of pterygium surgery with or without collagen matrix implantation," IOSR Journal of Dental and Medical Sciences, vol. 15, no. 7, pp. 20-25, 2016.

[25] H. Khlif, H. Zeghidi, and P. Rapp, "Interest of the biodegradable collagen matrix implant in surgical excision of pterygium," Investigative Ophthalmology \& Visual Science, vol. 53, no. 14, p. 4027, 2012.

[26] R. S. Rubinfeld, R. R. Pfister, R. M. Stein et al., "Serious complications of topical mitomycin-C after pterygium surgery," Ophthalmology, vol. 99, no. 11, pp. 1647-1654, 1992.

[27] S.-E. Ti and D. T. H. Tan, "Tectonic corneal lamellar grafting for severe scleral melting after pterygium surgery," Ophthalmology, vol. 110, no. 6, pp. 1126-1136, 2003. 